\title{
The New Mexico Consortium of Academic Libraries, 1988-1990
}

\author{
By Susan Oberlander \\ Director, Learning Resource Center \\ Northern New Mexico Community College
}

\begin{abstract}
A new network makes its first moves and devises a funding formula for academic libraries.
\end{abstract}

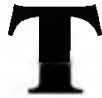

he story of a group forming to share resources is always good news. In New Mexico, a big western state with few resources and many miles between libraries, the recent successes of the new Consortium of Academic Libraries (NMCAL) have surprised both its supporters and critics in the world of higher education.

The factors leading to the formation of this Consortium are nebulous, and possibly disputable. For this participant, it seemed as if NMCAL came into existence despite all odds. NMCAL stands alone as a unique organization. Unlike Alabama's Network of Alabama Academic Libraries (NAAL), NMCAL did not have support or participation from the administrations of the academic institutions involved. Nor did it represent a relatively homogeneous group such as the graduate research libraries of NAAL. There was no history in this state of multitype library systems connected through the State Library or any other regional governing body. No direct lines of communication or staff representation to the state's Commission on Higher Education existed. Most importantly, we did not have much money or much technology.

What did we have? We had a small margin of acceptance, which we enlarged as fast as possible. In 1988, the New Mexico Commission on Higher
Education published a report called Planning for the Class of 2005, which was a contextual analysis of higher education in New Mexico. The report contains 166 recommendations in 32 different policy areas. Libraries are mentioned in two of the recommendations. The first calls for the establishment of consortia to address specific needs and to foster cooperation, resource sharing, and cost efficiencies. The second advocates creation of a new funding formula for libraries.

New Mexico also had a handful of librarians interested in political and technical cooperation. The New Mexico Library Association authored a Long-Range Automation Plan in 1988. Two participants from that process played a large role in the formation of NMCAL-Hiram Davis, then Dean of Libraries at New Mexico State University, who represented the six four-year academic libraries in the state, and this author, who, as the President of the Learning Resource Center Council, represented the directors of the 17 two-year college libraries.

A major task facing NMCAL's organizers was achieving mutual cooperation by the libraries of the two- and four-year colleges. These two groups have dissimilar missions as well as vastly different levels of money and prestige. Past misunderstand- 
ings had made each institution fairly suspicious of the others. Throughout the preliminary steps of writing bylaws and electing officers, we continually worked on communications and addressing vested interests to make sure that we had the support of each group, and indeed, were representing them equitably.

The stated purpose of the Consortium was to represent a unified position on key issues and to work on common projects. An Executive Board of six members was elected to represent the two-year libraries, the four-year libraries, and the non-voting associate members, including private schools. Standing committees responsible to the Executive Board were created in the areas of resource sharing, collection development, automation, and statistics. At the same time, NMCAL began the process of attaining political power. NMCAL felt neither opposition nor support from the various bodies it wanted to influence. NMCAL quickly established working relationships with some of the staff of the Commission on Higher Education. We chose one of the library recommendations from the Commission's report as our first project and began creating a revised funding formula for academic libraries. We visited a local legislator about our work and were asked to testify on behalf of the newly revised formula to his Committee on Higher Education. We also began attending the task force meetings of the two- and four-year college administrators who were considering what changes to make in the existing funding formula.

From all of this we learned some valuable lessons about influencing adversarial groups such as legislators, Commissioners of Higher Education, and college and university presidents. For one thing, we found that each group believed itself to be omnipotent. This actually was helpful to NMCAL since it was possible for members of each group to believe that their approval would cause the others to fall into line, an idea which seemed to give each of them some pleasure. We emerged victorious from the 1990 legislative session with a formula that will increase total library acquisitions budgets in the state by at least $\$ 2.9$ million per year when the formula is fully phased in.

\section{Creating the new funding formula}

The consortium had to tackle a project that would make the new organization valuable to its members and create a presence in the world of higher education in New Mexico. The Executive Committee of NMCAL felt that the project to create a new formula for funding was viable for two reasons: (1) it had received some sanction by virtue of the Commission on Higher Education's report, and (2) a poll of NMCAL members had determined that the priority need among them was for increased funding for acquisitions. The rationale for the recommendation was the need to recognize the library requirements of individual academic programs and the specific costs of library operations and materials.

A similar attempt in 1984 to create a funding formula for academic libraries in New Mexico had not succeeded. The existing funding formula simply lumped libraries into a category called Academic Support, which included academic administration, rather than employing a separate funding formula for libraries. This category was funded at $20 \%$ of the money received by the institution for instruction. The amount calculated for instruction was based on the institution's FTE. Funding based solely on FTE, of course, has certain inherent flaws for collection development. If enrollment, and thus budgets, drops too dramatically, the library cannot maintain the collection levels it has dedicated to support academic programs. Even if budgets are later restored, it is almost impossible to make up for collection deficits suffered during the lean years.

The formula used in the failed 1984 attempt still looked very good to the NMCAL Executive Committee. Our first step was to go to the principal author of the 1984 formula and explore with her how she had created the formula and why. The more we discussed it with her, the more we were convinced that it was a viable formula and that the previous attempt had failed for reasons other than the worthiness of the formula. It looked like this:

\section{A. Acquisitions}

- The acquisition rate shall be based on the Association of College and Research Libraries' Standards for College Libraries (1986) for fouryear schools and ACRL's (then in-force) Statement on Quantitative Standards for Two-year Learning Resources Programs (1979) for two-year schools. A collection standard for each library will be calculated based on the national standards. Each library will be given an annual replacement rate of $5 \%$ of the collection standard.

- To calculate the total acquisitions dollars, the number of acquisitions units (5\% of collection standard) shall be multiplied by a composite book/ periodical average price derived from the Bowker Annual (book index).

\section{B. Staffing: \\ Four-Year Schools}

- The staffing factor shall be based on a core staffing of 12.5 FTE with cumulative increments built on workload demands as follows:

1. Technical Services staffing is based on the level of acquisitions to be processed. The formula 
provides one FTE for each 700 acquisitions units.

2. Public Services staffing is based on weighted student FTE. The formula provides one FTE for each 450 weighted student FTE. The weighted student formula is as follows: lower division- 1 ; upper division-2; graduate- 4 .

3. Administrative staffing is based on the number of staff to be supervised. The formula provides one FTE for each eight technical or public services staff.

- Compensation for the staffing units generated above shall be calculated at the current average salary, including benefits, of the library staff of the six institutions.

\section{Two-Year Schools}

- The staffing factor shall be based on the following table of core staff, developed from current staffing in the institutions:

\begin{tabular}{lcc}
\hline FTE & $\begin{array}{c}\text { Professional } \\
\text { Staff }\end{array}$ & $\begin{array}{c}\text { Support } \\
\text { Staff }\end{array}$ \\
\hline
\end{tabular}

\begin{tabular}{lll} 
Under 1,000 & 1 & 2 \\
$1,000-2,000$ & 2 & 3 \\
$2,000-3,000$ & 3 & 4 \\
\hline
\end{tabular}

- Compensation for the staffing units generated above shall be calculated at the current average salary, including benefits, of the library staff of all the institutions.

\section{Nonsalary Expense}

- A percentage shall be calculated to determine how much should be generated by this formula to cover nonsalary expenses-that is, everything in current operating budget that is not salary or acquisitions. This percentage shall be calculated by using current operating budgets and dividing the nonsalary expenses by the total salary and acquisitions lines.

\section{Total Library Budget}

- The total library budget shall be determined by adding the acquisition, staffing, and nonsalary lines.

This formula contains what NMCAL views as an important concept to academic libraries. It assesses the amount needed for annual collection development in each library by assigning an ideal collection size, a replacement percentage, and a method for adjusting a unit price based on inflation. Therefore, even if the ideal collection size does not change over time, the library's acquisitions budget will keep up with inflation. The formula would be adjusted annually to reflect actual prices of materials. NMCAL believes that this type of formula will help administrators see the budget for library acquisitions as a quantifiable expense and not a black hole into which larger and larger amounts of the budget disappear.

In the other categories (i.e., staffing and nonsalary expense) NMCAL hoped to maintain existing levels, except at the four-year institutions where use of the formula would increase staffing due to an increase in acquisitions expenditures.

Figures for staffing in the formula were based on existing levels of staff. No attempt was made to increase staffing levels because it was believed that such an increase would not be acceptable to anyone but NMCAL. Thus, no effort was made to determine what equitable staffing levels might be, or even if current levels were inequitable.

Another limitation of the formula is that it makes no allowances for equipment or automation needs. There is no factor for equipment anywhere in the current funding formula. This is an issue that was not successfully resolved by the time of the 1990 budget recommendations to the legislature. The Commission on Higher Education continues to struggle with this problem. Libraries will certainly benefit when a factor for equipment is introduced into the formula. Automation was considered an appropriate item to be addressed by special funding devices (e.g., bonds or special appropriations) and not an item that could easily be factored into a formula that generated the operating budgets for many libraries. Automation needs are so different in each library that a common, equitable factor could not be developed. However, if there was a line item for automation in an existing budget, it was not necessarily lost under the new formula, since the nonsalary expense factor attempts to replicate all parts of a current budget that are not salary or acquisitions.

NMCAL came out of the 1990 session with a funding formula recommended by the Commission on Higher Education and accepted by the legislature for a phase-in period of three years. The formula for two-year schools went through intact, so that now library budgets are generated according to a separate funding formula for libraries. (The other institutional costs formerly covered under "Academic Support" are now funded at a lower percentage of instructional expenses.) Because of opposition to staff increases, the funding formula for four-year schools uses only the acquisitions component and adds it to the existing Academic Support budgets. The increase to existing acquisi- 
tion budgets will be $\$ 2.9$ million each year when the formula is fully phased in.

While we are encouraged with the success of this project, there are some pitfalls. For one thing, the formula was not fully funded in the first year, and we must anticipate that the schedule for phasing in the full funding over the next two years could go awry. One of the main complaints heard in discussions of formula funding is that states are rarely able to fund them at their full amounts. It is difficult to know in such a case if progress has been made. If the formula is never fully funded, are we better off knowing that all our members fall equally short of their goal? Or were we better off before, when each library received according to the ability of the school to give?

Some librarians have the misconception that the new formula creates a tamper-proof line item that is guaranteed for library use. That is certainly not the case. The legislature appropriates money to each institution based on the workload factors in the library formula. The institution still has the authority to spend the money according to what the board and the president agree are needs and priorities. In the first year the new formula was used, more money went into library budgets. There was not an absolute correlation between increases created by the new formula and increases in the library acquisitions budgets, but they were close. In future years, when the heightened awareness created by the recent revisions no longer exists, it is possible that administrators will feel more urgency to spend appropriations on other needs.

These limitations of formula funding in no way dim the enthusiasm of NMCAL and its members for the new funding formula for academic libraries. We hope to build on our success with that project to achieve other goals. This year we have chosen two projects based upon the Long-Range Automation Plan that will lead to enhanced resource sharing among our members. The first is called Project DATA and is viewed as a passive retrospective conversion plan. The target audience for this project is the two-year college libraries, which maintain current, working collections of materials and for the most part are not going to be involved in any large retrospective conversion efforts. The goal of

\section{OSS conference}

On July 11 and 12, 1991, the National Archives will sponsor the first major scholarly conference on the role of the World War II intelligence agency, the Office of Strategic Services (OSS). The conference is part of the Archives' nationwide commemoration of the 50 th anniversary of the American participation in World War II. this project is to produce MARC records for all new acquisitions to facilitate future networking efforts. It is felt that after five years of creating MARC records for all new acquisitions and weeding the collection consistently, most of the holdings records in these libraries will be machine-readable. This project will affect the seven two-year libraries that currently have no way of producing MARC records for their new acquisitions. We hope to provide them the mechanism for creating records, probably Bibliofile, by winning an LSCA Title III grant from the State Library.

Our second goal from the Long-Range Automation Plan is Project RECON. This project will encourage and assist local efforts to convert records of significant older materials into MARC format. The project establishes criteria for weeding that a library must satisfy in order to apply for a grant to assist retrospective conversion efforts. NMCAL believes collection assessment and weeding will be crucial to the retrospective conversion process. Sponsoring a workshop on collection assessment led by Nancy Powell from the Pacific Northwest Collection Development Program, was an initial step by NMCAL to help members learn collection assessment techniques.

NMCAL is also interested in some immediate step that could be taken to draw our members into the beginning stages of networking. All the obvious benefits of resource sharing and coordinated collection development will accrue only if a means of accessing all the titles held by our members is available-i.e., through a shared or linked database. While an online environment is a future possibility in New Mexico, NMCAL is reluctant to sit back and wait until all the necessary components for such a venture are in place.

Therefore, NMCAL is in the preliminary stages of writing a proposal for a Higher Education Act, Title II-D grant to fund a project that we hope will give us forward motion in the direction of an online network. This is a CD-ROM union list of the 2.2 million machine-readable records that currently exist among NMCAL's 26 members. The advantages of this project are: (1) it will allow our members to conduct a first merge of the machinereadable records that are currently available; $(2)$ it will give our members who do not have online catalogs but do have the ability to create machinereadable records, a place to put those records; (3) it will create a climate of expectation among our patrons and governing bodies that will make them more receptive to the costs and complexities of a future online statewide network; (4) it will give impetus to the work of making logical geographic connections for enhanced interlibrary loan arrangements and more efficient document delivery systems; and (5) it is affordable and doable right now. 